\title{
Comprehensive Utilization Pattern of the Bohai Rim Coastline Using the Restrictive Composite Index Method
}

\author{
Yun Zhang $\mathbb{D}^{1}{ }^{1}$ Tong $W u\left(\mathbb{D},{ }^{1}\right.$ and Yuanzhi Ye ${ }^{2}{ }^{2}$ \\ ${ }^{1}$ National Marine Environmental Monitoring Center, No. 42, Linghe Street, Shahekou, Dalian 116023, China \\ ${ }^{2}$ Zhejiang Academy of Surveying and Mapping, No. 2, Dixin Road, Wuchang Street, Yuhang, Hangzhou 310023, China
}

Correspondence should be addressed to Tong Wu; twu_dl@163.com and Yuanzhi Ye; xiaozhiyyz@hotmail.com

Received 28 July 2020; Revised 21 September 2020; Accepted 4 March 2021; Published 12 March 2021

Academic Editor: Jianhong (Cecilia) Xia

Copyright (c) 2021 Yun Zhang et al. This is an open access article distributed under the Creative Commons Attribution License, which permits unrestricted use, distribution, and reproduction in any medium, provided the original work is properly cited.

\begin{abstract}
Coastlines play an important role in human activity and economic development. Reasonably allocating shoreline resources and addressing contradictions between ecological protection and development are critical issues. In this study, positive and negative factors affecting the natural, environmental, and socioeconomic status of the coastal zone while considering land and sea effects were comprehensively analyzed using ecological theories and methods, and an improved restrictive composite index model was constructed. We quantitatively analyzed the comprehensive utilization pattern of the Bohai Rim coastline, China, in terms of the coastline utilization type and spatial agglomeration characteristics. The comprehensive utilization pattern of the Bohai Rim coastline is as follows: ecological areas are present in the north and south, and industrial areas are present in the east and west. Industrial production areas along the coastline are mainly distributed in the East Liaodong and Bohai bays, and ecological protection areas are located in the estuaries of the Liaohe and Yellow River. The improved restricted comprehensive index method model weakens the interaction among variables and makes the calculation results closer to the real situation. The results of the comprehensive utilization pattern of Bohai Rim coastline obtained by quantitative evaluation are of great significance for the coordinated development of coastline ecological protection and development and utilization.
\end{abstract}

\section{Introduction}

The coastlines of a country are valuable, scarce, and nonrenewable land resources. They are the backbones of maritime activities, tourism, and economic development [1]. However, in the last several decades, the relationship between the land and sea has become increasingly complex as global natural resources have been exploited further and the global population has burgeoned, resulting in a significant deterioration of the environment [2]. Since the 1970s, international scholars have studied the evolution of coastline environments from multiple perspectives and scales. After 1970, Dal Cin and Simeoni [3] and Tuda et al. [4] have investigated resource deterioration caused by urban development. Wright and Short [5], Blodget et al. [6], Lin [7], and Robinson [8] analyzed long-term coastline use and the shoreline evolution of neighboring beaches by employing historical topographic maps and multiphase aerial photography. Adler and Inbar [9], Andersen et al. [10], and Murray et al. [11] investigated prioritized types of coastline utilization and their influence on ecological functions. During the same period, Chinese scholars mainly focused on the geographical investigation of the development of coastlines and their spatial evolution. Using geographic information system (GIS) and remote sensing (RS) tools, Zhang [12], Wu et al. [13], Xu et al. [14], Wu et al. [15], and Ciritci and Türk [16] studied the changes of coastlines under the influence of natural and anthropogenic factors. Song and Liu [17], Li et al. [18], Yang et al. [19], and Du et al. [20] conducted local-scale research in the Bohai Rim region in the Hubei Province, Binhai New Area in Tianjin, and Laizhou Bay, respectively, to investigate the spatial distribution, status of development, and utilization of coastlines. 
However, few studies have focused on the spatial distribution and model development for the comprehensive utilization of the Bohai Rim coastline with regard to the dual influence of the land and sea. In previous studies that attempted to identify comprehensive utilization methods, most evaluation factors were static or single. In this study, we employed the restrictive composite index method, a paradigm borrowed from ecological research, to investigate the comprehensive utilization of the Bohai Rim coastline by combining natural, environmental, and socioeconomic factors affecting the health of the coastal zones. The promotion of high-quality sustainable economic development of the ecological environment in the Circum-Bohai-Bay region is of great significance.

\section{Study Region and Data Sources}

2.1. Study Region. The Bohai Rim refers to the economic zone comprising the coastal areas surrounding the Bohai Sea and Huanghai Sea [21]. The rim includes the sea and land areas of the Liaoning, Hebei, and Shandong provinces as well as Tianjin city, with a range of $35^{\circ} \mathrm{N}-41^{\circ} \mathrm{N}, 117^{\circ} \mathrm{E}-126^{\circ} \mathrm{E}$. The region has unique geographical advantages and abundant marine resources, providing a habitat for many species of birds and fish making it of high ecological importance [22]. According to the 2017 China Marine Statistical Yearbook [23], the region has a population of 230 million people, accounting for $16.9 \%$ of the total population of China. Its gross ocean product (GOP) is 2463.8 billion Yuan, which accounts for $31.7 \%$ of the gross national product. The Bohai Rim has become the engine of economic growth in North China and is the next focus of the national economic strategy after the Pearl and Yangtze River deltas. As many coastline development strategies have been implemented in recent years, the scale and intensity of marine resource utilization in coastal areas have been continually increasing. This has intensified the tension between supply and demand in the marine space, exacerbated conflicts of marine resource use across industries, while also placing substantial pressure on eco-friendly coastal protection measures and marine management $[24,25]$.

2.2. Data Sources. The present study aims to identify the effects of marine resource protection, development, and utilization of coastlines. Under the theoretical framework of land-sea coordinated and protective planning, we established an index matrix to study the utilization pattern of the Bohai Rim coastline using eight suitability and three restriction indexes. This matrix is based on several factors including the natural, environmental, socioeconomic, and regional characteristics of the Bohai Rim area (Tables 1 and 2). Data on functional zoning of marine area, coastal development planning, and use of marine area were obtained from the planning documents and sea-use records approved by the State Council of China and local governments of the coastal provinces. Data on the coastline length, type, and development intensity is based on the author's previous studies [26, 27]. We obtained the basic information of coastline from the high-resolution ( $2 \mathrm{~m}$ ) imagery remotely sensed in 2018 from GF-1, GF-2, and ZY-3, after preprocessing the image. Specifically, Canny edge detector was used to detect the coastline $[28,29]$.

\section{Materials and Methods}

3.1. Restrictive Composite Index Method. This study follows the methodology of an ecological suitability evaluation: the composite index method. This means that the suitability indexes were screened and converted into individual indexes of the same metric, which were subsequently weighted in accordance with the analytic hierarchy process [30]. The sum of the products is the composite evaluation index as follows:

$$
S=\sum_{i=1}^{n} X_{i} W_{i}
$$

where $S$ is the composite evaluation index, $X_{i}$ is the value of the $i$-th evaluation index, and $W_{i}$ is the weight of the $i$-th evaluation index.

The new model divides the evaluation indexes into the suitability and restrictive indexes. According to Yang et al. [19], the term ecological red line represents "the ecological bottom line required by a sustainable development strategy and ecological civilization" [19, 31, 32]. Based on this concept, the variable $R$ is defined according to the restrictive index matrix representing the short-board effect; that is, the index matrix acts as the limiting factor [33]. This variable is multiplied with the composite evaluation index, yielding the final comprehensive coastline utilization index SI (Figure 1).

Based on the revision of equation (1), the restrictive composite index can be obtained as follows:

$$
S I=\left(\sum_{i=1}^{n} X_{i} W_{i}\right) R,
$$

where $S I$ is the comprehensive coastline index, $X_{i}$ is the value of the $i$-th suitability evaluation index, $W_{i}$ is the weight of the $i$-th suitability evaluation index, and $R$ is the value of the restrictive factor of individual coastline areas.

\subsection{Value Assignment and Weighting}

(1) Calculation of the assigned values $(X)$ and weights $(W)$ of the suitability indexes: the coastline areas were ranked in four tiers, high, moderate, low, or not suitable, according to the effect of the indexes on the development and utilization of coastlines and were allocated the values of 7, 5, 3, and 1 , respectively. The assignment is based on the common scoring method for suitability evaluation by the expert group to develop and utilize coastline resources [34]. The value assignment, with the protection of the natural environment as its main purpose, considers the resource destruction on coastlines caused by human interference, state of the coastlines ecological balance, and load-bearing and regenerative capacities of the marine environment. The assignment process 
TABLE 1: Classification values and weights of the suitability indexes.

\begin{tabular}{|c|c|c|c|c|}
\hline Primary index & Secondary index & $\begin{array}{l}\text { Assigned value } \\
(X)\end{array}$ & Suitability & $\begin{array}{l}\text { Weight } \\
(W)\end{array}$ \\
\hline \multirow{3}{*}{ A1 coastline type } & B1 artificial & 5 & Moderate & \multirow{3}{*}{0.0752} \\
\hline & $\mathrm{B} 2$ rocky, B3 sandy, B4 slit/muddy, B5 estuary & 3 & Low & \\
\hline & B6 biological & 1 & None & \\
\hline \multirow{3}{*}{ A2 water quality } & B7 class I, B8 class II & 7 & High & \multirow{3}{*}{0.0178} \\
\hline & B9 class III, B10 class IV & 5 & Moderate & \\
\hline & B11 below class IV & 3 & Low & \\
\hline \multirow{4}{*}{$\begin{array}{l}\text { A3 coastline development } \\
\text { intensity }\end{array}$} & B12 heavily developed & 7 & High & \multirow{4}{*}{0.0495} \\
\hline & B13 moderately developed & 5 & Moderate & \\
\hline & B14 slightly developed & 3 & Low & \\
\hline & B15 undeveloped & 1 & None & \\
\hline \multirow{4}{*}{$\begin{array}{l}\text { A4 functional zoning of } \\
\text { marine area }\end{array}$} & B16 industrial and urban & 7 & High & \multirow{4}{*}{0.1427} \\
\hline & B17 mineral and energy, B18 ports and transports & 5 & Moderate & \\
\hline & $\begin{array}{c}\text { B19 agricultural and fishery, B20 special use, B21 touristic and } \\
\text { recreational }\end{array}$ & 3 & Low & \\
\hline & B22 protected area, B23 reserved area & 1 & None & \\
\hline \multirow{3}{*}{$\begin{array}{l}\text { A5 coastal development } \\
\text { planning }\end{array}$} & B24 industrial development & 7 & High & \multirow{3}{*}{0.1472} \\
\hline & B25 ecocity & 5 & Moderate & \\
\hline & B26 coastal tourism & 3 & Low & \\
\hline \multirow{2}{*}{$\begin{array}{l}\text { A6 protection status of } \\
\text { marine area }\end{array}$} & $\begin{array}{l}\text { B27 protection pilot zone, B28 moderate utilization zone, B29 } \\
\text { ecological and resource restoration zone }\end{array}$ & 3 & Low & \multirow{2}{*}{0.2753} \\
\hline & $\begin{array}{c}\text { B30 buffer zone, B31 core area, B32 key protection zone, B33 reserved } \\
\text { area }\end{array}$ & 1 & None & \\
\hline \multirow{2}{*}{$\begin{array}{l}\text { A7 regional sea-use } \\
\text { planning }\end{array}$} & B34 constructional & 7 & High & \multirow{2}{*}{0.1472} \\
\hline & B35 agricultural reclamation & 5 & Moderate & \\
\hline \multirow{4}{*}{ A8 use of marine area } & B36 reclamation & 7 & High & \multirow{4}{*}{0.1451} \\
\hline & B37 industrial, B38 transportation & 5 & Moderate & \\
\hline & B39 salt industry, B40 fishery & 3 & Low & \\
\hline & B41 tourism and recreation, B42 special use & 1 & None & \\
\hline
\end{tabular}

TABle 2: Restrictive index classification and variable values.

\begin{tabular}{lcc}
\hline Index & Regulatory zoning & Variable value $(R)$ \\
\hline Marine ecology protection red line & No development & 0 \\
& Restricted & 1 \\
\hline & No development & 0 \\
National major functional zone & Restricted & 1 \\
& Upgrading & 3 \\
\hline & Key & 5 \\
National major marine functional zone & No development & 1 \\
& Restricted & 3 \\
\hline
\end{tabular}

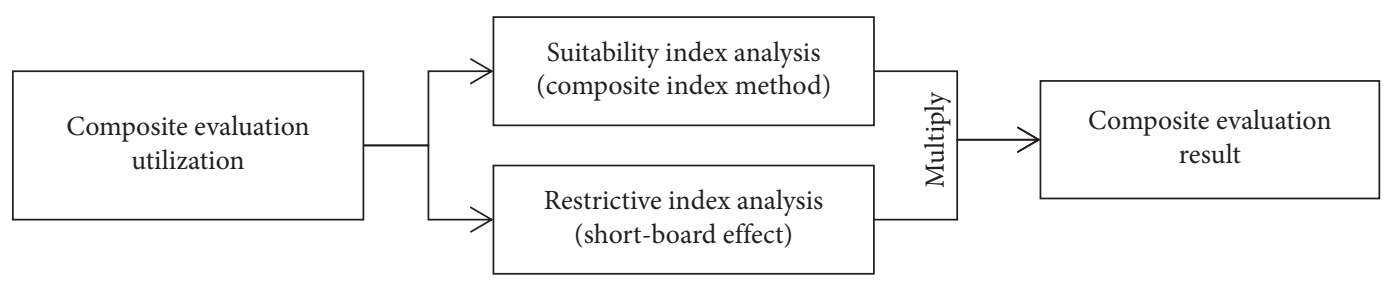

FIGURE 1: Basic principle of the improved restrictive composite index method. 
assumes the principles of interconnected development planning, coordination between the land and sea environments, centralized deployment, and economical utilization of coastline resources.

Weights were calculated for eight suitability indexes based on an analytic hierarchy process, where index pairs were compared regarding their significance and were evaluated layer by layer to construct a decision matrix (Table 1). The eigenvector corresponding to the largest eigenvalue was subsequently derived using the square root method to determine the weight of a single index against the total goal. The consistency ratio of the decision matrix was 0.0108 , indicating a highly satisfactory result.

(2) Calculation of the restrictive index variable $(R)$ : the weighting factors describe the contribution of a particular index to suitability. The weights presented here follow the "extreme value principle" [35], which reflects the sensitivity of the regional ecological environment to human activities. To decrease regulatory constraints with regard to regulatory zoning, the indexes were grouped into a no development zone, restricted development zone, optimized development zone, and key development zone, with variable values of $0,1,3$, and 5 , respectively (Table 2 ). When the restrictive indexes overlapped during the calculation of the comprehensive utilization suitability index, SI, the index with the highest restriction value prevailed. This was based on the "extreme value" and "short-board" rules, which also conform to the "limiting factor law" in ecology [36].

\subsection{Types of Comprehensive Utilization of Coastlines.} Based on the application of the restrictive composite index method, which yields the extreme value of each index, the coastline comprehensive utilization index $(S I)$ falls within the range of $0-17.2452$. Based on this number and the state of resource protection and development along the coastlines, the comprehensive utilization of coastlines was classified into four coastline types: ecological protection, public access and recreation, livelihood security, and industrial production (Table 3).

(1) Ecological protection coastlines refer to coastal areas designated for ecology preservation where marine development is prohibited. These coastlines are located along biologically important habitats or within marine protection/reservation zones, core areas of natural protection, and clean sea areas.

(2) Public access and recreation coastlines are accessible to the public for relaxation and spiritual experiences. They mainly serve the tourism industry and have recreational functions, while also providing opportunities for open-agriculture and fishery activities. They include natural coastlines, estuaries, clean sea areas, open-agriculture/fishery zones, special-use zones, tourist and recreational zones, coastal tourism zones, and natural protected zones.
(3) Livelihood security coastlines refer to coastal areas that are developed to provide basic livelihood, residential, and educational functions to citizens. They are usually located near areas of urban residential, agricultural reclamation, fishery, salt production, transportation, research, education, or dumping.

(4) Industrial production coastlines are mainly designated for industrial production and infrastructure construction. Artificial coastlines and coastlines located near areas of construction, industrial, mineral, energy, and port/transportation sea belong to this category.

\section{Results}

4.1. General Features of the Spatial Distribution of the Coastlines. The length and spatial distribution of the categorized Bohai Rim coastline estimated using the restrictive composite index method are shown in Figure 2. The ratios of coastline lengths of ecological protection, public access and recreation, livelihood security, and industrial production coastlines are $17.70 \%, 19.88 \%, 35.44 \%$, and $26.98 \%$, respectively.

The overall pattern of the spatial distribution can be summarized as "ecological in the south and north, industrial in the east and west, red lines in the inner areas, and green zones in the outer areas." The coastline utilization types are shown in Figure 3:

(1) Ecological protection coastlines are concentrated mainly in Dalian, Yantai, and Dongying, which account for $50 \%$ of the total length of ecological protection coastlines. Such coastlines are usually clustered around estuaries and coastal wetlands, such as the estuaries of the Liaohe and Yellow rivers.

The areas of ecological protection coastlines are of great significance to the sustainable development of Marine ecology. All activities of coastline development and utilization are strictly prohibited within the scope of the region, except for key planning and construction such as administrative management, proper tourism service foundation, scientific research, and education. It is suggested to strengthen the ecological assessment work in the region, especially in the area of human activities, to detect and prevent the deterioration of the coastal ecological environment in time.

(2) Public access and recreation coastlines are mainly located in Weihai, Dalian, and Qingdao, which account for $59 \%$ of the total length of this type of coastline. Their spatial distribution characteristics indicate that such coastlines are common in cities with dominant tourism and recreation functions.

The areas of ecological protection coastlines are based on natural shoreline, clean sea, open sea, and other tourist and recreational areas. The construction and development pay equal attention to ecological protection. We should follow the principles of green, 
TABLE 3: Criteria for the classification of comprehensive utilization types of coastlines.

\begin{tabular}{lcccc}
\hline Classification & Ecological protection coastline & $\begin{array}{c}\text { Public access and recreation } \\
\text { coastline }\end{array}$ & $\begin{array}{c}\text { Livelihood security } \\
\text { coastline }\end{array}$ & $\begin{array}{c}\text { Industrial production } \\
\text { coastline }\end{array}$ \\
\hline Suitability index $(S I)$ & $0 \leq S I \leq 2.2742$ & $2.2742<S I \leq 3.6427$ & $3.6427<S I \leq 11.2125$ & $S I>11.2125$ \\
\hline
\end{tabular}

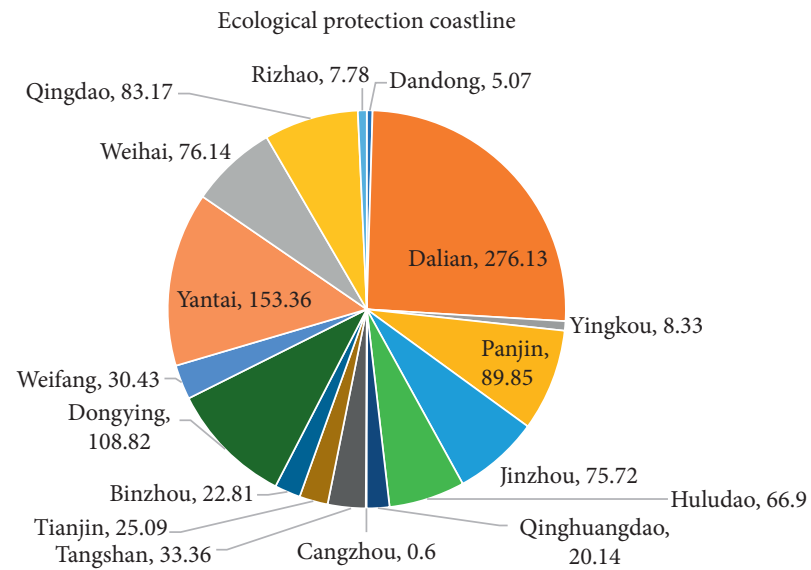

(a)

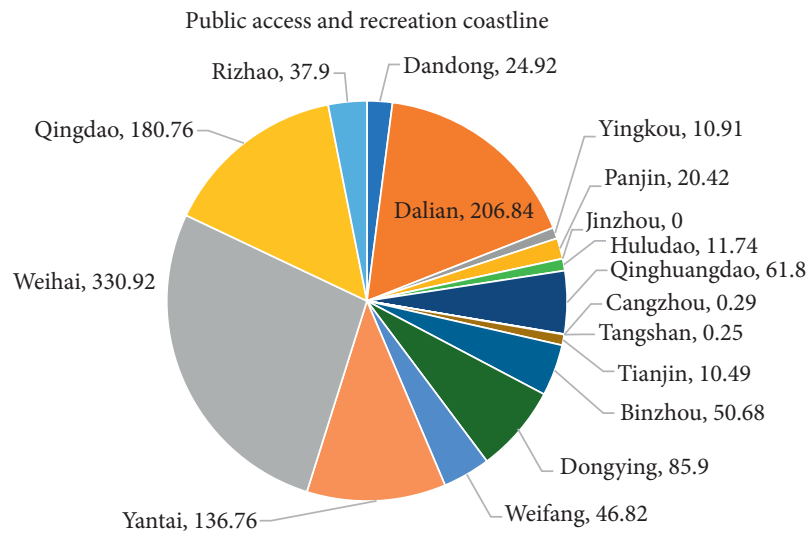

(c)

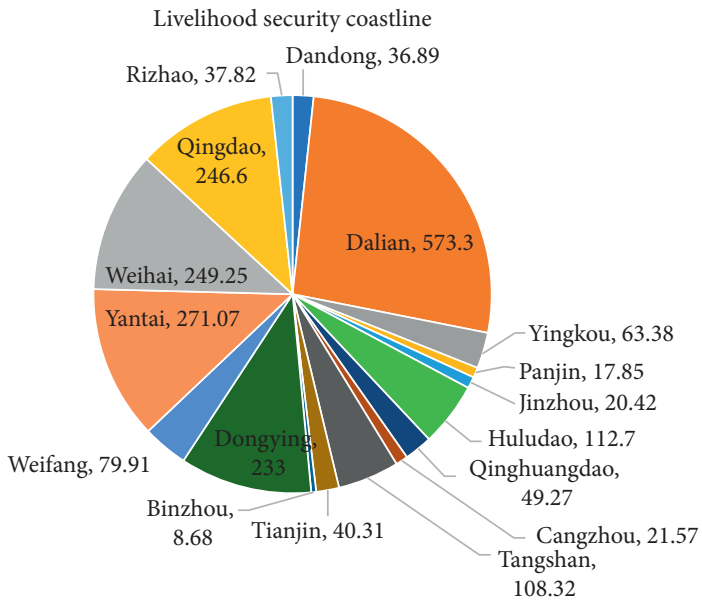

(b)

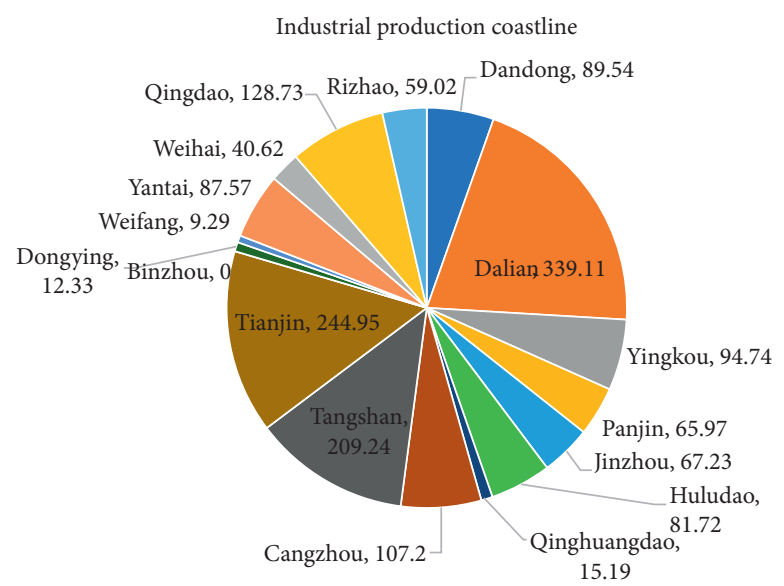

(d)

FIgURE 2: Length and distribution of all types for comprehensive utilization at the Bohai Rim ( $\mathrm{km}$ ).

open, and sharing and give priority to ecological protection. Proper tourism, leisure, and entertainment infrastructure should be built in these areas, and appropriate guidance should be given to the centralized development of some open agricultural, fishery, and marine activities.

(3) Livelihood security coastlines are located in Dalian, Yantai, and Weihai around the Huanghai Sea, and account for $50 \%$ of the total length of this type of coastline. These coastlines are mainly aquaculture sites.

Through the adjustment of land and sea industrial structure, this region should promote the optimization of urban land and sea industrial structure and improve the utilization efficiency of coastline. It is suggested to strengthen the scientific and technological innovation of the traditional agricultural, fishery, and marine industry to enhance its economic output. Through the guidance of macro policies, we should actively promote marine development activities that are beneficial to the improvement of human settlements. Restrict or put an end to marine development activities that cause high pollution or damage to the ecological environment.

(4) Industrial production coastlines are mainly located in Dalian, Tianjin, and Tangshan around the eastern flank of the Liaoning and Bohai bays, accounting for $48 \%$ of the total length of such coastlines. They typically house industrial production construction sites and shipping port/supporting facilities.

In this region, the advantageous industries in this region should be promoted to develop into clusters. 


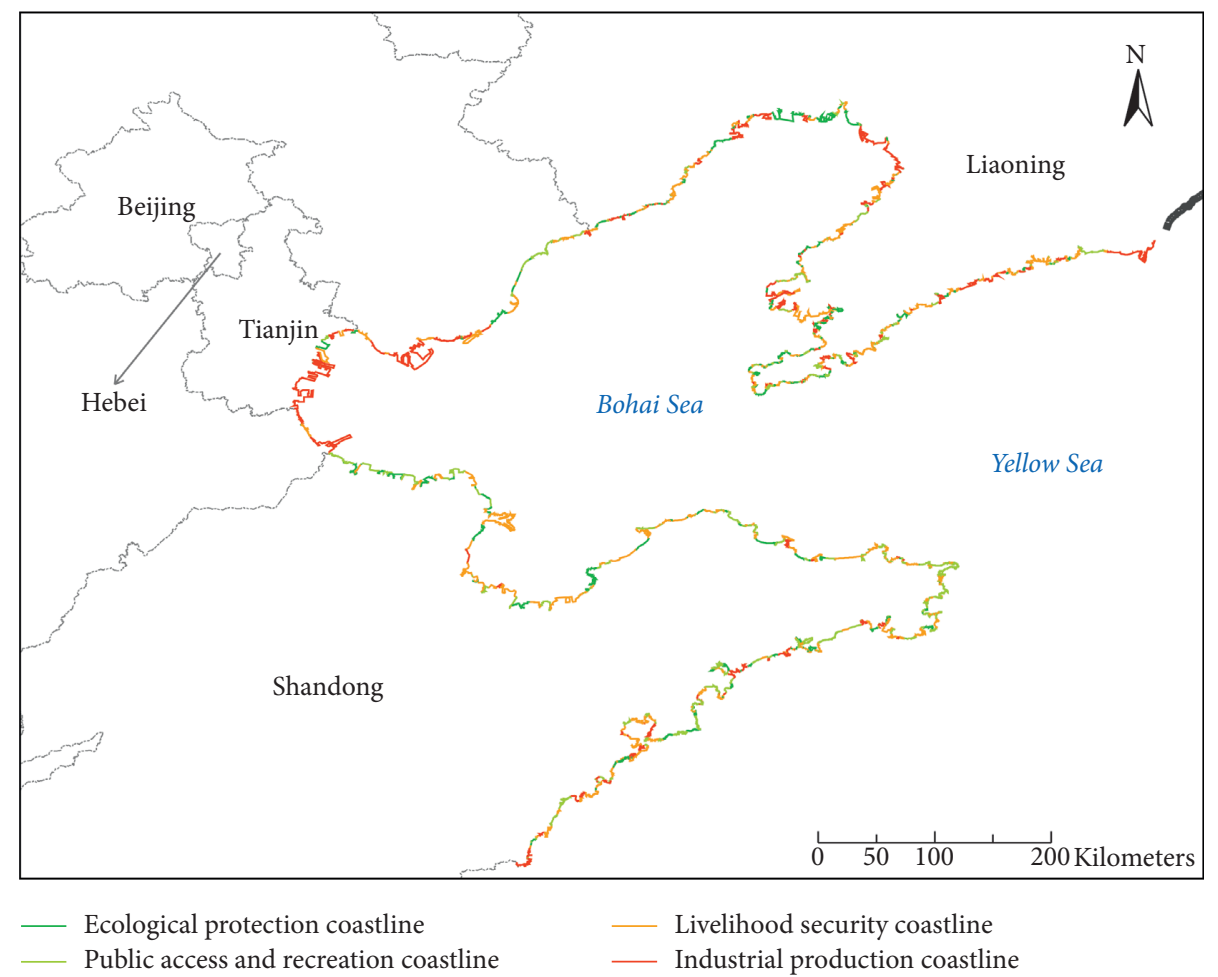

Figure 3: Spatial distribution of comprehensive coastline utilization types at the Bohai Rim.

It forms a coordinated division of labor and cooperation with the industrial development space in the land and strengthens the sharing of supporting facilities and industrial cooperation. It is suggested to strengthen the intensive and economical utilization of the coastline and promote the development of offshore and green industrial sea. Prevent industrial land and sea low density, decentralized spread to the destruction of the ecological environment, in order to achieve the maintenance of the shoreline ecological health development.

4.2. Differences in the Spatial Distribution in Province-Level Administrative Regions. The spatial distributions of comprehensive coastline utilization types in each administrative division (Figures 2 and 3 ) indicate that coastlines in Liaoning and Shandong mainly belong to the livelihood security type, whereas those in Hebei and Tianjin mainly belong to the industrial production type. These coastlines account for $34.94 \%, 40.00 \%, 52.87 \%$, and $76.35 \%$ of the total coastline length in their respective provinces (municipalities). Detailed distribution patterns for each administrative region are described below:

(1) The ratio of ecological protection coastlines, public access and recreation coastlines, livelihood security coastlines, and industrial production coastlines in the Liaoning Province is $2: 1: 3: 3$. Ecological protection coastlines are dominant in Jinzhou and Panjin, livelihood security coastlines are dominant in Dalian and Huludao, and industrial production coastlines are dominant in Dandong and Yingkou. These three dominant coastline types comprise $40 \%$ $60 \%$ of the total coastline length, whereas public access and recreation coastlines are distributed among the six coastal cities.

(2) More than half $(52.87 \%)$ of the coastlines in Hebei Province belong to the industrial production type, located mainly in Tangshan and Cangzhou. Ecological protection coastlines and public access and recreation coastlines are mostly located in Qinghuangdao, accounting for $55.97 \%$ of the total city coastline. Livelihood security coastlines are distributed among these cities.

(3) At least $75 \%$ of the coastlines in Tianjin belong to the industrial production type; the other three types comprise the remaining portion.

(4) The coastlines in Shandong are mainly livelihood security and public access and recreation coastlines, which cover over $70 \%$ of the total coastline. Livelihood security coastlines are mainly located in the Laizhou and Jiaozhou bays. Ecological protection and public access and recreation coastlines have similar spatial distribution patterns; they are mostly located in Binzhou, Yantai, Weihai, and Qingdao. Industrial production coastlines can be found in the Huanghai area, specifically in Qingdao and Rizhao.

\section{Discussion}

5.1. Comparison of Applied Methods. The effects of the assessed indexes on the comprehensive utilization of the 
coastlines are either positive, which can allow development opportunities, or negative, which can lead to the total restriction or prohibition of coastline utilization. Currently, comprehensive utilization evaluation methods are increasingly diversifying and evaluation scopes are expanding. Previous studies have evaluated the comprehensive utilization of land and space resources [37-39], but few are applied to coastlines. Moreover, most evaluation factors are static or singular [40,41]. Dynamic and complex factors are typically not considered in coastlines studies as most consider differences in quantity rather than quality.

Therefore, we developed an improved restrictive composite index model, which utilizes two types of evaluation index factors: suitability and limitation. Based on the application of this method to investigate the comprehensive utilization pattern of coastlines, problems arise with regard to the inconsistency with real-life situations and the reliability of the model; therefore, both these areas need to be addressed for improvements in future studies.

We obtained the comprehensive utilization pattern for the Bohai Sea coastline based on the principle of delineating the ecological red line and "short-board effect." However, the calculation of the weights and thresholds of various indicators is insufficiently accurate and necessitates future research to validate the data.

5.2. Data Indicator Limitations. The comprehensive utilization of coastlines is affected by multiple regional development factors. In this study, the classification results are limited to the selection of indicators and assessment of the data reliability in the Bohai Rim region. Portions of the data on coastal economic development planning and marine protected areas were obtained by the interpretation of macro-scale data. In addition, coastline resources and the environment are directly and indirectly affected by both the land and sea. The verification of the effects of indirect forces requires a considerable amount of environmental data. Environmental factors must be further optimized and analyzed at macro- and microscopic spatial scales using grid technology.

\subsection{Index Assignment and the Rationality of Classification} Results. Index assignment is mainly based on common scoring methods used by experts for suitability evaluation, such as the Delphi method and linear weighted sum method, which inevitably have some subjective elements [34]. But it has reference significance for the analysis of the comprehensive utilization of the coastline of medium and macro scale. The calculation of weights and thresholds of various indicators needs to be verified by a large amount of data in future research to make it more reasonable.

\section{Conclusions}

In this study, eight suitability and three restriction indexes were selected based on several factors including the natural, environmental, socioeconomic, and regional characteristics of the Bohai Rim area. The restrictive comprehensive index method was used to study the comprehensive utilization patterns of the Bohai Rim coastlines. The results provide a scientific basis for the promotion of sustainable marine economic development and the rational utilization of coastline resources. The main conclusions are presented below:

(1) The restrictive composite index model reduces the conflicts and contradictions among many indexes by restricting the factor variables. The results are closer to the objective real values.

(2) The results of the classification of the coastline uses and the restrictive index variables correlate well. The classification results of four types of coastlines depend on the coverage of restrictive indicators and control zones.

(3) The utilization of the coastlines around the Bohai Rim presents the characteristics of cluster-type belt agglomeration. The development patterns of four types of comprehensive coastline utilization zones (ecological protection, public access and recreation, livelihood security, and industrial production coastlines) are consistent with the development strategy of the "Circum-Bohai-Bay region."

The results reveal the spatial distribution pattern of ecological protection and resource development of the coastlines around the Bohai Rim, enabling the identification of new patterns, as well as the development direction and strategy regarding the comprehensive utilization of coastlines. It is significant to determine the relationship between ecological protection and resource development of coastlines to provide a scientific basis for the promotion of sustainable marine economic development and rational utilization of coastline resources. The results will provide guidance regarding the rational and orderly spatial distribution of the marine economy around the Bohai Rim.

\section{Data Availability}

The datasets used and analyzed during the current study are available from the corresponding author on reasonable request.

\section{Conflicts of Interest}

The authors declare that there are no conflicts of interest regarding the publication of this paper.

\section{Acknowledgments}

This work was supported by the National Natural Science Foundation of China (Grant no. 41876109) and China Association of Marine Affairs (Grant no. CAMAJJ201810).

\section{References}

[1] F. Li, K. Cao, J. H. Zhao, and D. R. Song, "Identification and characteristics of typical coastline indicators: a case study of 
the central coast of Jiangsu Province," Geographical Science, vol. 16, pp. 963-971, 2018.

[2] T. Wu and X. Y. Hou, "Review of research on coastline changes," Acta Ecologica Sinica, vol. 36, pp. 1170-1182, 2016.

[3] R. Dal Cin and U. Simeoni, "A model for determining the classification, vulnerability and risk in the southern coastal zone of the Marche (Italy)," Journal of Coastal Research, vol. 10, no. 1, pp. 18-29, 1994.

[4] A. O. Tuda, T. F. Stevens, and L. D. Rodwell, "Resolving coastal conflicts using marine spatial planning," Journal of Environmental Management, vol. 133, pp. 59-68, 2014.

[5] L. D. Wright and A. D. Short, "Morphodynamic variability of surf zones and beaches: a synthesis," Marine Geology, vol. 56, no. 1-4, pp. 93-118, 1984.

[6] H. W. Blodget, P. T. Taylor, and J. H. Roark, "Shoreline changes along the Rosetta-Nile Promontory: monitoring with satellite observations," Marine Geology, vol. 99, no. 1-2, pp. 67-77, 1991.

[7] J.-C. Lin, "Coastal modification due to human influence in south-western Taiwan," Quaternary Science Reviews, vol. 15, no. 8-9, pp. 895-900, 1996.

[8] E. Robinson, "Coastal changes along the coast of Vere, Jamaica over the past two hundred years: data from maps and air photographs," Quaternary International, vol. 120, no. 1, pp. 153-161, 2004.

[9] E. Adler and M. Inbar, "Shoreline sensitivity to oil spills, the Mediterranean coast of Israel: assessment and analysis," Ocean \& Coastal Management, vol. 50, no. 1-2, pp. 24-34, 2007.

[10] J. H. Andersen, B. S. Halpern, S. Korpinen, C. Murray, and J. Reker, "Baltic Sea biodiversity status vs. cumulative human pressures," Estuarine, Coastal and Shelf Science, vol. 161, pp. 88-92, 2015.

[11] C. C. Murray, S. Agbayani, H. M. Alidina, and N. C. Ban, "Advancing marine cumulative effects mapping: an update in Canada's Pacific waters," Marine Policy, vol. 58, pp. 71-77, 2015.

[12] Y. Zhang, "Coastal environmental monitoring using remotely sensed data and GIS techniques in the Modern Yellow River delta, China," Environmental Monitoring and Assessment, vol. 179, no. 1-4, pp. 15-29, 2011.

[13] C. Wu, C. Huang, G. Liu, L. Chu, Q. Liu, and J. Zhao, “Coastal line change and driving force analysis of Bohai Rim region based on remote sensing," Ocean Development Management, vol. 5, pp. 30-36, 2015.

[14] N. Xu, Z. Gao, and J. Ning, "Spatial-temporal variations of coastlines in Bohai Rim based on fractal dimension and their causes analysis," Journal of Marine Sciences, vol. 34, pp. 45-51, 2016.

[15] P.-Q. Wu, J. Zhang, Y. Ma, and W. Sun, "Coastline dynamics monitoring and analysis around the Bohai sea using remote images during 2010 and 2015," Advances in Marine Science, vol. 36, no. 1, pp. 128-138, 2018.

[16] D. Ciritci and T. Turk, "Analysis of coastal changes using remote sensing and geographical information systems in the Gulf of Izmit, Turkey," Environmental Monitoring Assessment, vol. 192, p. 341, 2020.

[17] S. Song and A. Liu, "Study on development utilization and protection of coastal line in Hebei Province," Ocean Development and Management, vol. 26, no. 9, pp. 43-46, 2009.

[18] X. Li, T. Zhang, Z. Zhang et al., "Development and utilization of the resources in the coast zones of Heibei Province," Chinese Journal of Agricultural Resources and Regional Planning, vol. 36, no. 4, pp. 104-112, 2015.
[19] Y. Yang, Y. Sun, and J. Du, "Spatial-temporal variation characteristics of Tianjin Binhai new area coastal zone from 2001 to 2013," Journal of Tianjin Normal University (Natural Science Edition), vol. 36, no. 5, pp. 46-50, 2016.

[20] P. Du, X. Wu, X. Du, B. Liu, and L. Yu, "Situation evaluation on the marine spatial development and utilization in the Laizhou Bay," Marine Science Bulletin, vol. 36, no. 1, pp. 19-26, 2017.

[21] S. Huang, The Research on the Marine Industry Structure Adjustment and Optimization in Bohai Rim Region, Ocean University of China, Qingdao, China, 2013.

[22] A. Suo, Y. H. Yu, and L. J. Miao, "Assessment of ecosystem service value in the Bohai Sea," Marine Economy, vol. 1, no. 4, pp. 42-47, 2011.

[23] People's Republic of China and State Oceanic Administration, China Marine Statistical Yearbook, China Ocean Press, Beijing, China, 2017.

[24] W. Zhai, W. Xu, Q. Wang, and L. Tan, "Current situation and characteristics of marine development in Tianjin and its impact on marine eco-environment," Ocean Development and Management, vol. 7, pp. 93-96, 2012.

[25] W. Zhai and J. Zhang, "Analysis of conditions features and problems of sea area utilization in China," Resource Science, vol. 35, pp. 405-411, 2013.

[26] Y. Zhang, J. L. Zhang, X. M. Li, X. D. Jing, and J. Yang, "Stability of continental coastline in China since 1990," Scientia Geographica Sinica, vol. 35, no. 10, pp. 1288-1293, 2015.

[27] Y. Zhang, J. Zhang, X. Jing, and J. Zhao, "Historical changes of the length and fractal dimension of Chinese coastline since 1990," Marine Environmental Science, vol. 34, no. 3, pp. 406-410, 2015.

[28] J. Canny, "A computational approach to edge detection," IEEE Transactions on Pattern Analysis Machine Intelligence, vol. 8, pp. 679-698, 1987.

[29] Y. Zhang, J. Zhang, X. Li, and D. Song, "A study on coastline extraction and its trend based on remote sensing image data mining," Abstract and Applied Analysis, vol. 2013, Article ID 693194, 6 pages, 2013.

[30] T. L. Saaty and L. G. Vargas, Models, Methods, Concepts and Applications of the Analytic Hierarchy Process, p. 175, Springer Science \& Business Media, Berlin, Germany, 2012.

[31] Y. Xu, B. Liang, C. G. Bao, D. D. Lan, C. Y. Yu, and M. H. Ma, "Research on the index system and the technical methods of ecological red line division for the Bohai Sea," Marine Science Bulletin, vol. 32, no. 4, pp. 361-367, 2013.

[32] F. Hu, Y. Q. Yu, Y. Zheng, and X. Yang, "An innovative study of ecological red line delimitation," Planners, vol. 5, p. 18, 2018.

[33] Z. Yang, A. Suo, Z. Zhang, X. Xu, and B. Wei, "Application and development countermeasures of "buckets effect" in the assessment of resources and environment carrying capacity," Marine Environmental Science, vol. 37, no. 4, pp. 602-607, 2018.

[34] J. I. Xue-Peng, X. J. Huang, Y. Chen et al., "Comprehensive suitability evaluation of spatial development and construction land in the perspective of land-ocean co-ordination: a case study of Liaoning Province, China," Journal of Natural Resources, vol. 34, no. 3, pp. 451-463, 2019.

[35] Y. Zhang, C. Wang, and K. Liu, "Applicability of different probability distributions to estimated extreme rainfall," Scientia Geographica Sinica, vol. 11, pp. 1460-1467, 2015.

[36] J. Hua, "The transfer and application of ecological law to biology classroom teaching," Biology Teaching, vol. 40, pp. 32-33, 2015. 
[37] T. Shi, G. Zheng, Z. Wang, and L. Wang, "Progress in research on land suitability evaluation in China," Progress in Geography, vol. 26, no. 2, pp. 106-115, 2007.

[38] H. Du, Z. Li, and Y. Zheng, "Research progress on assessment of resources and environment bearing capacity and suitability of land space development," China Min. Magazine, vol. 28, no. 2, pp. 159-165, 2019.

[39] A. Reza Pilevar, H. R. Matinfar, A. Sohrabi, and F. Sarmadian, "Integrated fuzzy, AHP and GIS techniques for land suitability assessment in semi-arid regions for wheat and maize farming," Ecological Indicators, vol. 110, p. 105887, 2020.

[40] L. Xu, J. Li, L. Yang, Q. Yuan, M. Wang, and P. Chen, "Integrated suitability evaluation on mainland coastline resources in Zhejiang Province," China Land Sciences, vol. 29, no. 4, pp. 49-58, 2015.

[41] J. Cai, X. Chen, Q. Zhang, and Q. Xu, "Study on exploitation suitability and development potential of river shoreline," Journal of Yangtze River, vol. 51, no. 1, pp. 36-43, 2020. 